\title{
LINGUAGEM MATEMÁTICA E COMUNICAÇÃ̃O: UM ENFOQUE INTERDISCIPLINAR
}

\author{
Mathematical Language and communication: an interdisciplinary focus
}

Marisa Rosâni Abreu da Silveira ${ }^{1}$

\section{RESUMO}

Este texto tem o objetivo de sugerir um enfoque interdisciplinar que visa à comunicação entre aluno e professor no processo de ensino e de aprendizagem da linguagem matemática. Esse enfoque é tratado sob o ponto de vista de diferentes olhares: o filosófico discute a natureza do objeto matemático; o antropológico aponta para a relação que o aluno estabelece com os objetos matemáticos e as suas representações; o histórico discorre sobre o discurso que fala da dificuldade da matemática; o psicológico destaca o processo cognitivo do aluno quando lida com conceitos matemáticos; e o semiótico trata das representações dos objetos matemáticos. Para tanto, analisa-se as implicações de algumas características da linguagem matemática nos processos de seu ensino e de sua aprendizagem, bem como se reflete acerca do papel da comunicação nesse processo que envolve os seguintes temas: a relação entre a língua natural e a linguagem matemática; e os jogos de linguagem como forma de vida para que haja a comunicação entre professor e aluno.

Palavras-chave: Língua Natural, Linguagem Matemática, Comunicação, Interdisciplinaridade.

\begin{abstract}
This paper aims to suggest an interdisciplinary approach that seeks to a communication between student and teacher in the teaching and learning of mathematical language. This approach is treated from different point of view perspectives: the philosophical discusses the nature of mathematical object, the anthropological points to the relationship that provides the student with mathematical objects and their representations, the historic talks about the discourse that speaks of difficulty of mathematics, the psychological stresses the student's cognitive process when dealing with mathematical concepts, and discusses the semiotic representations of mathematical objects. Therefore, it is analyzed the implications of some features of mathematical language in the processes of teaching and their learning, and reflects on the role of communication in this process involving the following topics: the relationship between natural language and mathematical language, and the language games as a way of life for which there is communication between teacher and student.

\footnotetext{
${ }^{1}$ Dra. em Educação pela UFRGS/Universidade de Paris. Professora Adjunta da Universidade Federal do Pará, no Programa de PósGraduação em Educação em Ciências e Matemáticas do Núcleo Pedagógico de Apoio ao Desenvolvimento Científico. E-mail: marisabreu@ufpa.br
} 
Key-words: Natural Language, Mathematical Language, Communication, Interdisciplinary.

\section{INTRODUÇÃO}

A interação entre aluno e professor depende da linguagem utilizada por ambos, pois é por meio do diálogo que pode haver comunicação. No processo de ensino e de aprendizagem da matemática, é preciso o entendimento, e, neste sentido, eles devem compartilhar do mesmo universo discursivo. Porém, a matemática como linguagem exige uma especial atenção no processo de seu ensino, já que ela é codificada e seus símbolos, muitas vezes, parecem não ter sentido para o aluno. A leitura atenta pelos educadores matemáticos dessa problemática tornase necessária para que sejam compreendidas quais as possibilidades de êxito do aluno no acesso ao discurso matemático. Não basta que o professor conheça o conteúdo matemático, é preciso que também conheça as características da linguagem matemática que implicam na aprendizagem do aluno.

Existem diversas abordagens que tratam da didática da matemática como disciplina e que oferecem subsídios aos professores para transporem os conteúdos matemáticos de forma que o aluno compreenda o saber a ser ensinado, como afirma Chevallard (2005, p. 16),

El concepto de transposcíon didáctica, en tanto remite al paso del saber sábio al saber enseñado (...) El saber-tal-como-es-enseñado, el saber enseñado, es necesariamente distinto del saber-inicialmente-designado-como-el-que-debe-serenseñado, el saber a enseñar.

Para tal feito, o saber matemático merece um olhar especial pelo educador. Nesse sentido, gostaria de destacar cinco abordagens que podem emergir do horizonte de possibilidades quando o professor ensina esse saber. Tais possibilidades oferecem uma visão interdisciplinar ao processo de ensino da matemática.

A primeira abordagem é a filosófica. O debate das diferentes correntes da Filosofia da Matemática é importante ser conhecido e refletido pelo professor, pois cada uma delas trata a natureza do objeto matemático com enfoques diferentes e, por consequência, o conceito do objeto matemático também pode ser construído/ensinado de diferentes maneiras.

A visão dos platonistas postula a existência a priori dos objetos ideais matemáticos, os intuicionistas postulam que os objetos ideais não existem a priori, mas são construídos conforme suas necessidades; e os formalistas também concordam que não existem os objetos ideais a priori, mas que nós podemos fabricar os axiomas em linguagem codificada. Segundo Caveing (2004), a matemática apresenta um movimento intrateórico, denominado automovimento, constituindo uma sucessão de descobertas. O mesmo autor observa que as entidades pré-existentes com necessidades próprias do movimento intrateórico da matemática e a construção de objetos por atividade inventiva do sujeito não podem ser separadas. $\mathrm{O}$ sujeito cria o conjunto dos números naturais e por uma necessidade interna da matemática cria/descobre o conjunto nos números inteiros.

Para Wittgenstein, o matemático não é um descobridor, mas sim, um inventor. Portanto, a matemática é inventada, trata-se de uma construção humana. Como prova de sua argumentação, afirma: "pode-se fazer um estudo antropológico de uma obra matemática, pois ela nos mostra como um determinado povo opera com os signos e que partes da matemática 
dominou este povo. A matemática é um fenômeno antropológico" (1987, p. 338). Para o filósofo, a matemática não precisa de fundamentos, sendo vista como uma prática humana. Wittgenstein (apud Chaurivé, 2004) salienta que a cerimônia do cálculo e o ritual da prova matemática mostram a "natureza" de animal cerimonial, fenômeno inerente ao sujeito de linguagem. Nesse sentido, percebemos uma visão da matemática ligada à antropologia, o que constitui a segunda abordagem que destaco.

Os estudos antropológicos contribuem para que possamos compreender o motivo pelo qual o aluno tende a se representar nas coisas e relacioná-las. Este fato pode ser relacionado com a dificuldade do aluno em ver o objeto matemático mesmo que disponha de sua representação. Por exemplo: pensar a negatividade (números negativos), bem como a ausência (o zero), pois o zero e o número negativo estão fora de seu campo de visão.

Lizcano (1993) faz uma análise entre o pensamento chinês, composto por analogias e oposições, e o pensamento grego, composto por abstrações. O complexo simbólico yin/yang trabalha com a determinação de opostos, enquanto que a dialética do ser e do não-ser impede a episteme grega de pensar a negatividade. Para Lizcano, o princípio de não-contradição (ser/não-ser) representa um "obstáculo epistemológico" na aprendizagem.

Conforme apresentei em minha tese de Doutorado, a dificuldade de pensar as pequenas e as grandes cifras é outro grande problema para o aluno. Um número pode ser tão grande a tal ponto de ser representado pelo infinito, enquanto outro número pode ser suficientemente pequeno, requerendo, assim, um nível de abstração que muitos alunos não atingem. Não conseguem abstrair justamente porque não podem ver que estes números e estes símbolos $(-\infty, \infty)$ surgem pela falta de configuração visual.

Percebe-se a dificuldade do aluno em representar aquilo que ele não vê e, consequentemente, de operar com estes elementos, sejam eles o zero, os números negativos, ou as grandes e as pequenas cifras. Nesse caso, a representação mental é totalmente prejudicada pela falta de representação visual. Como o aluno não consegue imaginar um objeto que ele não pode visualizar, o professor deverá propor estratégias que facilitem tal percepção.

A construção de conceitos matemáticos remete à atividade de um sujeito que cria um objeto que antes não existia e que cria regras no processo de construção dos conceitos. A criação de regras matemáticas, na perspectiva do aluno, está associada a uma espécie de magia e é destacada por Stela Baruk (1996) nas suas pesquisas em escolas francesas. Wittgenstein (1987, p.87) percebe este fato afirmando que o resultado do cálculo está previamente fixado, assim como a cartomante prevê os fatos, daí a ideia do "mistério" que envolve a matemática. "No es como si viéramos en una operación de cálculo una espécie de cartomancia?".

A ideia de 'mistério', 'magia' e 'salvação' têm suas raízes na própria história da matemática e constitui a terceira abordagem na educação matemática que destaco. Para Silveira (2000), a história da matemática nos mostra que o mito de que a matemática é difícil é resultante de re-significações atribuídas a fatos históricos que marcaram o campo da disciplina, agregada à visão utilitária do seu saber e que desembocam na ciência matemática e as suas relações de poder. Para Pitágoras, "os números governam o mundo", para Napoleão Bonaparte "os homens são como os algarismos, só têm valor pela sua posição" (Upinsky, 1989, p. 3) e consequentemente a maioria dos alunos adere a esse discurso portador desse mito de dificuldade e dizem "matemática não é para mim", - parafraseio aqui a expressão utilizada Bourdieu e Passeron (1992, p.166) "isso não é para nós" quando retratam o pensamento dos excluídos no interior da escola. 
A matemática também teve um caráter religioso: a matemática, vista por Pitágoras e Platão, tem conotação diferente da matemática vista na escola atual. Porém, aqueles contribuiram, de certa forma, para que, nos processos de re-significação da matemática, ela seja vista como disciplina reservada a poucos. Pitágoras, portanto, em lugar do deus Dioniso colocou a matemática e Platão afirmava que "Deus sempre geometriza".

Comte enxergava a matemática de sua época como "um edifício pronto e acabado". Segundo Silva (1994), o início do ensino superior da matemática no Brasil se deu com a criação da Academia Real Militar do Rio de Janeiro, em 1810. Esse ensino permaneceu ligado às academias militares e escolas de engenharia até 1934. O ensino da matemática servia para divulgar uma filosofia, e assim formou-se uma nova classe, constituída por militares que viam nos ensinamentos de Comte uma forma de realizar os seus anseios de "ordem e progresso".

O quarto enfoque que destaco é o psicológico, já que o conhecimento matemático é aprendido através de processos cognitivos. A teoria do conhecimento busca compreender a relação do sujeito com as coisas que estão fora dele (a realidade) e o social (o outro). Essa relação acontece através do uso da lógica e da intuição; por meio desta, pode-se inventar e daquela pode-se demonstrar. De-monstrar é uma mostração, mostrar o objeto matemático e suas propriedades como foram percebidos. Assim, a evidência matemática ou e-vidência é utilizar a visualização do objeto por meio da proposição ou por à vista por meio do símbolo matemático. O processo intuitivo aflora o processo de abstração que se dá, quando o objeto é pensado sem que ele esteja presente. Sabendo imaginar o objeto na sua ausência, o sujeito pode oferecer instrumentos à intuição na produção de imagens de outros objetos semelhantes. Para Piaget (1974, p. 19), a "abstração reflexiva, que caracteriza o pensamento lógicomatemático, é ser tirada não dos objetos e sim das ações que se pode exercer sobre eles e, essencialmente, das coordenações mais gerais destas ações". Assim, podemos perceber que a abstração é fruto da criatividade humana e que as leis lógicas, segundo os intuicionistas, derivam da linguagem matemática.

O quinto enfoque a ser destacado é o semiótico, pois os objetos matemáticos passam a existir na medida em que eles são construídos e representados por meio de registros. As representações semióticas dos objetos matemáticos têm como um dos propósitos a comunicação da forma como o aluno apreendeu tais objetos, pois essas representações mostram como eles foram interiorizados nos processos de desenvolvimento das representações mentais. O processo de apreensão desses objetos constitui o conceito de tais objetos. Duval (1975) salienta que existe um paradoxo nesse processo de construção do conceito, pois questiona como o sujeito aprendente pode não confundir o objeto matemático com a sua representação se ele apenas dispõe de sua representação.

Os cinco enfoques aqui destacados nortearão este texto cujo objetivo é refletir sobre os problemas que ocorrem na interação professor-aluno nos processos de conversão da linguagem matemática em linguagem natural e vice-versa. Em primeiro lugar, pretendo discorrer sobre as implicações da linguagem matemática no seu processo de ensino e aprendizagem, e nesse sentido, torna-se necessário tratar da sua objetividade e o seu processo de formalização, como também, discutir o surgimento das regras matemáticas e o problema de suas interpretações e aplicações. Em segundo lugar, pretendo refletir sobre o papel da comunicação nesse processo e que envolve os seguintes temas: a relação entre a língua natural

\footnotetext{
2 A matemática também está associada à questão de gênero, pois ela tinha um caráter masculino já que se prestava, inclusive ao estudo das estratégias bélicas e, assim foi introduzida em academias militares frequentadas na época apenas por homens. Assim, evidencia-se o motivo pelo qual essa disciplina, até hoje, tem uma construção masculina.
} 
e a linguagem matemática, como também, os jogos de linguagem como forma de vida para que haja a comunicação entre professor e aluno.

\section{A LINGUAGEM MATEMÁTICA}

A linguagem matemática se desenvolve na escrita e é uma construção subjetiva, já que deriva da intersubjetividade e se objetiva por meio de símbolos. As experiências do sujeito são intuitivamente descritas através da fala e envolvem variações, devido ao fato da linguagem natural ser polissêmica e estar associada à afetividade. A escrita é mais difícil que a fala porque através dela tentamos expressar nossos pensamentos que a oralidade desempenha com mais fluidez, pois no discurso podemos retomar as palavras que possam ter sentido equivocado ou ambíguo para o ouvinte. Já na escrita, temos que ser o mais objetivo possível para que o leitor interprete de maneira adequada aquilo que pretendemos comunicar.

A linguagem matemática, por sua vez, com a pretensão de ser universal, necessita de maior objetividade para evitar a polissemia da linguagem e buscar um sentido único. Para que isso aconteça, é necessário certo rigor na sua forma de argumentação e esse rigor é buscado nos símbolos matemáticos que, na maioria das vezes, são atravessados por uma linguagem standartizada.

A história nos mostra que tem sido quase impossível o trabalho em matemáticas sem a utilização de uma simbologia. Esse fato se revela na tradução da linguagem natural para a linguagem escrita que é, de certo modo, a forma oral codificada em símbolos matemáticos. Apesar do necessário rigor para evitar as ilusões da intuição, Granger (1974, p. 139) argumenta que "o que se ganha em rigor, perde-se radicalmente em eficácia".

A escrita serve para recordar e transmitir ideias e conceitos através de registros. "A escrita, na expressão científica, já não é um código: é a própria matéria da linguagem". (Granger, 1975, p. 79). O que é escrito já não é seguramente mais pertencente ao escritor, e sim, está sujeito às diversas interpretações de seus leitores e inclusive do próprio autor que não é mais o mesmo sujeito no momento em que escreveu seu texto. Esse fato se justifica porque a escrita se distancia do curso das representações mentais sem a intuição primeira. Em matemática, podemos nos perguntar: por que um aluno da Educação de Jovens e Adultos sabe fazer cálculos mentais, mas não sabe formalizar a operação feita mentalmente? É provável que ele tenha se habituado a fazer cálculos mentalmente, sem a necessidade de escrevê-los, diferentemente de outro adulto que tenha, desde a mais tenra idade, aprendido a escrever números, fazer contas e aplicar algoritmos por meio da escrita.

Outra pergunta aqui é pertinente: por que um aluno que trabalha no comércio, por exemplo, sabe calcular o troco ao seu cliente corretamente, mas na escola não sabe resolver cálculos semelhantes? Além do processo de formalização que se evidencia como o mesmo motivo do aluno da EJA, esse aluno se depara com outra problemática que é a mudança de contexto. No cotidiano, na condição de comerciante, o sujeito está num determinado contexto; na sala de aula, na condição de aluno, o contexto é outro. De acordo com Wittgenstein (2000, p. 31), "quando os jogos de linguagem mudam, há uma modificação nos conceitos e, com as mudanças nos conceitos, os significados das palavras mudam também".

O jogo de linguagem consiste de linguagem e pelas atividades com as quais ela vem entrelaçada. No jogo, "uma parte grita as palavras, a outra age de acordo com elas" (Wittgenstein, 1996, p. 18). Desta forma, o significado da palavra se dá no uso, na sua aplicação. 
O aluno comerciante ao dar o troco de dois bombons ao freguês que lhe oferece uma nota de cinco reais sabe que se um bombom custa 50 centavos, dois bombons custarão um real e que deverá dar quatro reais de troco. Na sala de aula, quando se depara com o cálculo 5 - 2 x 0,50, talvez não ele saiba resolvê-lo. $O$ aluno na condição de comerciante vive a experiência desses números, na condição de aluno ao se deparar com uma expressão formalizada não lhe remete a uma experiência vivida e consequentemente não sabe resolvê-la.

A língua formalizada é organizada segundo as estruturas sintáticas. A palavra em matemática, ou o conjunto de palavras, fornece uma relação entre conceitos. Para Granger, as interpretações das significações se dão na experiência que é objetivante. Os símbolos comportam os sentidos que é o conjunto de suas próprias leis formais. Assim, "mudar de código, traduzir, fazer corresponder a um texto de uma língua um texto de outra língua, lhe conservando o 'sentido' e, eventualmente, talvez algo mesmo da 'significação"” (1974, p. 171). Na língua formalizada, a experiência do sujeito com seus símbolos e a apreensão do seu sentido começa com a sintaxe e se completa com a semântica, pois a estrutura abstrata se presta à objetivação da experiência, com as instâncias vividas de uma experiência a ser objetivada.

\section{A objetividade da linguagem matemática}

Segundo Frege (1983), a objetividade pertence à lógica e a subjetividade pertence às leis psicológicas. No entremeio da objetividade da matemática e a subjetividade do aluno, percebemos que não pode haver objetividade sem subjetividade. Para Caveing (2004), a objetividade da matemática não é fundamentada na experiência, ela é anterior à experiência, já que na objetivação de procedimentos existe uma circularidade entre os atos do sujeito que constituem os objetos no processo de objetivação e, a criação de conceitos dos objetos que se regram por meio de um movimento autônomo. Nesse sentido, o sujeito cria conceitos numa liberdade limitada. Para o filósofo, o automovimento da matemática, que é dado pela historicidade da matemática, é o lugar onde pode ser colocado o problema do modo específico da historicidade do objeto matemático. O automovimento das matemáticas é uma sucessão de descobertas de entidades pré-existentes com necessidades próprias. Essas descobertas e a construção de objetos por atividade inventiva do matemático, não podem ser separadas.

As necessidades próprias do universo teórico da matemática e a "autonomia radical, no sentido de uma regulação puramente interna, ou seja, de uma auto-regulação perfeita" citada por Piaget (1974, p. 7) ao comentar a formalização na matemática são, de certa forma, discutidas por outro viés por Bouveresse (1987) que analisa a força da 'regra' e a invenção da necessidade na filosofia da linguagem de Wittgenstein. $O$ filósofo afirma que a regra impõe uma necessidade objetiva e, dessa forma, pode-se inferir que inventamos o conjunto dos números naturais e por consequência inventamos o conjunto dos números inteiros por uma necessidade conceitual da matemática.

De acordo com as diferentes correntes filosóficas, existem distintas formas de conhecermos o objeto matemático, porém para a maioria dos filósofos, a objetividade revela uma intersubjetividade, pois o conceito do objeto é uma forma lógica cristalizada no discurso. Para Panza (1995), o conceito libera um conteúdo que se transforma em um objeto matemático por um ato de objetivação que corresponde à construção de um sistema formal. $\mathrm{O}$ significado é subjetivo com sentido construído na intersubjetividade e sedimentado na estrutura da linguagem. Um objeto matemático não é uma entidade atribuitivamente última e suas atribuições dependem do conceito, na medida em que é a definição que o revela. Dessa 
forma, conceito é objetividade e o processo de objetivação oferece ao conceito a passagem do objeto e, nesse sentido, há uma cristalização do objeto em conceito.

\section{A formalização matemática e suas representações semióticas}

Granger (1975) afirma que o pensamento formal é uma dialetização do pensamento intuitivo que reduz a linguagem como uma maneira de formalizar a experiência e que depende de uma compreensão e "engendramento" de conceitos. A intuição com as condições formais da sensibilidade, num movimento dialético com o objeto (fenômeno), representa $\mathrm{o}$ pensamento formal, ou seja, dá forma ao conteúdo da experiência. A redução da linguagem que formaliza a experiência conectora dos conceitos compreendidos nasce na intuição, logo torna objetivo o que antes era subjetivo.

Assim, formalizar é materializar o conteúdo da experiência. "O pensamento formal parece-nos consistir desde então essencialmente na construção de uma sintaxe cada vez mais precisa, a partir de uma semântica privativa, que faz corresponder a nomes e coisas ainda mal definidas" (Granger, 1975, p.75). Para o filósofo, por consequência, toda redução ao formal apresenta um resíduo que é interpretado além do texto matemático. Assim, a linguagem matemática pode ser representada por símbolos que remetem a diversos conceitos que devem ser lidos e interpretados, mas que não estão necessariamente escritos no texto.

A aquisição do conhecimento matemático passa pela representação do objeto no qual está atrelado o conceito do objeto. Nesse contexto, as representações mentais geralmente têm origens nas representações semióticas interiorizadas.

Re-apresentar o objeto por meio de um registro significa apresentar o objeto utilizando outro objeto e que, segundo Duval (2003, p. 16), a compreensão matemática supõe dois registros de representação semiótica: "os tratamentos [que] são transformações de representações dentro de um mesmo registro (...), por exemplo, resolver uma equação" e as conversões que "são transformações de representações que consistem em mudar de registro conservando os mesmos objetos denotados (...), por exemplo, passar da escrita algébrica de uma equação à sua representação gráfica". O autor salienta que treinar um sentido de conversão não implica que a conversão do outro sentido seja compreendida, já que o aluno tem dificuldade de reconhecer o objeto matemático em suas diferentes representações, mas que o acesso aos objetos matemáticos passa necessariamente por representações semióticas.

O pensamento que é um tipo de linguagem é decodificado através de regras de correspondência e é re-apresentado por meio de um registro de representação semiótica, ou seja, o sujeito imagina o objeto e o transforma em conteúdo formal, dá forma ao conteúdo do pensamento e codifica em outra linguagem.

\section{COMUNICAÇÃO EM MATEMÁTICA}

A comunicação inclui a linguagem natural em simbiose com a linguagem matemática. Segundo Wittgenstein, a matemática se funda nos jogos de linguagem e é explorando tais jogos entre professor e aluno que a linguagem matemática pode ser compreendida e os conceitos matemáticos podem ser construídos. O significado de uma proposição matemática ultrapassa a linguagem no sentido de que é necessário buscar outras proposições que a expliquem, pois o significado é o papel da palavra para o sujeito que a interpreta. Quando é preciso decodificar a proposição, traduzi-la para a linguagem natural, começa o entendimento 
do seu significado que se dá por meio do processo de tradução do simbolismo matemático para as palavras da língua natural.

A tradução pode ser feita por gestos e por palavras ou até mesmo traduzir em outro modo de representação. O signo é dinâmico e o seu sentido é o seu propósito no enunciado, mas que está sujeito a diversas interpretações. Porém, não é na tradução que as palavras fazem sentido, e sim no uso das palavras, pois o significado não está no texto e sim no uso do texto, num contexto. É no uso, não na tradução, que a palavra faz sentido. A interpretação nesse sentido é dada em signos, sejam matemáticos ou não, mas que depende do sentido que o interpretante carrega.

Quando Granger afirma que a sintaxe deve completar-se com a semântica, podemos aferir que as regras gramaticais e as regras matemáticas se complementam, pois a sintaxe da língua matemática se completa com as regras matemática implícitas nos seus enunciados.

Para que haja interpretação, é necessário que o sujeito tenha acesso ao discurso do outro. Na linguagem matemática, quando o enunciado afirma "Dada a reta tal....", "Seja a função tal...", quem é o sujeito deste discurso? Segundo Foucault (1995), o sujeito do discurso da matemática é indeterminado. De acordo com o autor, podemos afirmar que o discurso da matemática é um discurso sem sujeito determinado e que limita o aluno ao acesso a este universo discursivo.

Além do simbolismo matemático e de seus processos interpretativos, de regras mágicas, na perspectiva do aluno, lidamos ainda com um discurso que o aluno não interage com o escritor do texto. As características da linguagem matemática e suas nuances são aspectos que discuto neste texto, para que juntamente com outros educadores possamos refletir o papel da linguagem matemática no processo de seu ensino e de sua aprendizagem.

Segundo Granger (1974), a comunicação da linguagem lógica formalizada é apenas virtual, pois a linguagem formal é desprovida de oralidade. A linguagem matemática necessita da linguagem natural para que seus símbolos adquiram vida.

O texto representado pelos seguintes símbolos $\forall x \in A, \exists ! y \in B /(x, y) \in A \times B$ pode ser traduzido da seguinte forma "para todo $x$ pertencente ao conjunto $A$, existe um e somente um elemento $y$ pertencente ao conjunto $B$, tal que o par ordenado de coordenadas cartesianas $x$ e $y$ pertence ao produto cartesiano $A x B$ ”. Podemos nos perguntar quem é o autor do texto e o que explica ao aluno essa tradução? Esse texto que apresenta um sujeito indeterminado e que é formalizado por meio de símbolos matemáticos comporta um resíduo que deve ser resgatado com a interpretação.

Caveing (2004), concordando com Granger, afirma que as matemáticas não constituem uma língua de comunicação. Assim, para que haja comunicação deve haver compreensão, entendida aqui como constructo de relações e significações pleno de sentidos, já a interpretação é simplesmente a explicitação do ato de compreender. O sujeito lê, compreende e interpreta, projeta sentidos na interpretação e novamente lê, compreende e interpreta; similar ao círculo hermenêutico de Heidegger. Dessa forma, o texto matemático lido, compreendido e interpretado com a intervenção da língua natural obtém sentidos por intermédio do diálogo do professor e do aluno.

A comunicação através do texto escrito exige a leitura e a interpretação mencionada acima já que a escrita matemática é mais complicada sem a intervenção da oralidade. Já para a construção de um texto matemático pelo aluno é necessário que haja uma pré-compreensão dos conceitos envolvidos para essa produção. A construção do texto é subjetiva e depende da imaginação do aluno, mas deve ser validada por argumentos conceituais nascidos da 
intersubjetividade e objetivada por meio da escrita. A autoria de textos matemáticos apenas se dá quando o aluno sabe ler e interpretar a linguagem matemática.

\title{
A língua natural e a linguagem matemática
}

A linguagem simbólica formal é substituída por uma linguagem natural standartizada, pois seus símbolos pretendem ter um sentido único, diferentemente da língua natural, em que a palavra é polissêmica. Nesse sentido, a linguagem matemática torna-se devedora de uma sensibilidade/subjetividade já que está atrelada a preceitos lógicos.

Granger (1975, p. 74) afirma que

\begin{abstract}
as matemáticas, com efeito, parecem mesmo reduzir-se a uma pura linguagem, porque o elemento sintáctico absorve o elemento semântico: os signos matemáticos não se referem já a objectos que transcendem a linguagem, mas as leis da sua própria estrutura. A significação de um símbolo tão simples como um algarismo não se reduz de modo algum à designação de um objecto determinado, de uma coleção tomada em si mesma.
\end{abstract}

O aluno pode ser autor de um texto matemático quando ele demonstra um teorema ou demonstra o resultado de um cálculo, porém a demonstração na matemática que segue a ilação "se $p$, então $q$; ora $p$, portanto $q$ ", não é imediata para o aluno, ela deve ser compreendida no contexto e ser interpretada no uso da produção textual e, segundo Caveing (2004), a demonstração resulta da construção de conceitos.

Nós, professores, não levamos em consideração a imaginação criativa do aluno que pode perceber o objeto com conceito $p$ e o objeto com conceito $q$ de maneiras distintas. Segundo Duval (1995, p.21),

\begin{abstract}
a linguagem natural e as línguas simbólicas não podem ser consideradas como formadoras de um só e mesmo registro. Igualmente, os esquemas, as figuras geométricas, os gráficos cartesianos ou as tabelas são sistemas de representação muito diferentes entre si e que colocam, cada um, questões de aprendizagens específicas (tradução nossa).
\end{abstract}

O aluno que não considera a adição de meia laranja mais meia laranja igual a uma laranja inteira, por exemplo, e que explica à professora que quando se corta a laranja ao meio, sempre cai um caldinho, não concorda com os símbolos $\frac{1}{2}+\frac{1}{2}=1$. Este exemplo esclarece a citação de Duval, pois a linguagem natural utilizada pelo aluno no cotidiano e suas experiências em cortar laranjas independem de registros semióticos justamente porque o cotidiano lhe ensina de uma forma e, na escola, a experiência em lidar com símbolos matemáticos é aprendida de outra forma.

Nesse sentido, é necessário que exista uma simbiose entre a língua natural e a linguagem matemática. Somente por meio do diálogo que professor e aluno podem participar do mesmo universo discursivo. O professor por meio do diálogo compreende a lógica do aluno e, a partir dessa aprendizagem, pode mostrar ao aluno que a lógica matemática é regida por regras que podem não coincidir com outra lógica. 
Todo o texto escrito em linguagem natural segue regras gramaticais e possui regras matemáticas implícitas no conjunto de suas palavras. $\mathrm{O}$ texto escrito em linguagem matemática deve ser traduzido para a linguagem natural para que tenha sentido. Entretanto, a interpretação dessa tradução também leva em conta as regras matemáticas implícitas.

As regras matemáticas seguem o imperativo categórico: "que seja assim!", mas caso esse imperativo seja aplicado de outra forma, o aluno estará aplicando outra regra. Aplicar uma regra corretamente é intuir a regra, mas pensar estar aplicando a regra, não é garantia de aplicá-la corretamente. "Nas regras do jogo não podem ocorrer nenhuma contradição" (Wittgenstein, 2003, p. 239). A relação matemática é feita por mediação de um sistema de regras, porém os alunos aplicam uma mesma regra em contextos diferentes e acabam modificando-a.

A invenção de regras se apoia em descobertas que são induzidas por necessidades conceituais (Wittgenstein apud Bouveresse, 1987), ou seja, as regras são aplicadas para satisfazer as necessidades teóricas da própria matemática. A regra se atualiza automaticamente em cada contexto, porém podemos não saber atualizá-la. Ao interpretar regras matemáticas, na perspectiva do aluno, quando muda o contexto, muda o conceito. A regra antes de ser interpretada pelo aluno obedece às exigências da matemática, após a interpretação depende da própria lógica do aluno.

\section{CONSIDERAÇÕES FINAIS}

Os aspectos destacados neste texto em relação à comunicação entre a linguagem matemática, a linguagem do professor de matemática e a linguagem do aluno que aprende matemática dentro de um enfoque interdisciplinar foram utilizados na tentativa de elucidar ao professor de matemática que o processo de ensino e aprendizagem não requer apenas conhecimentos de conteúdos matemáticos, mas de mostrar que esse processo depende de alguns conhecimentos da própria história da matemática, de alguns conhecimentos de linguagem e comunicação, bem como de alguns conhecimentos filosóficos e antropológicos.

A regra matemática que afirma que $a b=b a$ não concorda com a regra gramatical, pois ela afirma que $a b \neq b a$. Este fato aponta que alguns equívocos durante o processo de ensino e aprendizagem podem ocorrer, sem que o professor tenha conhecimento e é por isso que deve estar atento à lógica que o aluno emprega ao interpretar os conceitos matemáticos. Um professor não admitiria que "há tantos cálculos em que os números não são mencionados" (Wittgenstein, 2003, p. 233), porém os oleiros estimam o volume de quantidade de material que cabe dentro de botijas de cerâmica sem utilizarem números. Esse fato mostra que o professor precisa considerar a etnomatemática que tem suas origens na antropologia.

A história da matemática nos mostra que é impossível o aluno reconstruir todos os conceitos matemáticos que levaram séculos para serem elucidados por matemáticos famosos.

Para Wittgenstein, a matemática se fundamenta num jogo de linguagem, mas ressalta que a matemática não é um jogo porque as regras já estão previstas. A matemática é um jogo segundo regras determinadas, pois o resultado já está previsto e fixado, porém, deve-se destacar que o caminho para esse resultado pode ser criado pelo aluno, quando usa sua imaginação, que é criativa. Achar a solução de um problema é dar sentidos aos conceitos envolvidos no enunciado. 
O significado do símbolo e da regra matemática se dá nos seus respectivos usos, por intermédio da leitura e da interpretação, e o sentido depende do contexto em que o símbolo e a regra matemática estão sendo empregados.

Wittgenstein ressalta que as expressões $1+1+1+1$ e $(1+1)+(1+1)$ têm o mesmo significado, mas sentidos diferentes. Esse fato nos aponta, mais uma vez, a atenção que devemos dar à linguagem matemática que tem suas características próprias.

Segundo Granger, o método da matemática é a ordem, já Foucault chama a matemática de ciência da ordem. Essa ordem é dada a priori, pois o aluno tem um caminho a seguir e deve obedecer ao automovimento da matemática.

Uma das grandes dificuldades do aluno é generalizar o conhecimento, ou seja, compreender o caminho dessa ordem que segue o automovimento da matemática e seguir uma regra matemática observando o contexto. A generalização na matemática estabelece a relação do particular para o geral, ou seja, explica o particular através de exemplos. $\mathrm{O}$ professor dispõe de exemplos para explicar ao aluno os caminhos que deve seguir e no processo dessa explicação deve convidá-lo a participar deste ritual de demonstrações, pois é a partir do diálogo que professor e aluno participam do mesmo jogo de linguagem e as palavras ditas por ambos têm os mesmos significados como uma forma de vida.

\section{REFERÊNCIAS}

BARUK, Stella. Insucessos e Matemáticas. Lisboa / Portugal: Relógio D’ Água Editores, 1996.

BOURDIEU, Pierre; PASSERON, Jean C. A reprodução. Rio de Janeiro: Frontes Alves, 1992.

BOUVERESSE, Jacques. La force de la règle: Wittgenstein et l'invetion de la necessité. Paris: Les Éditions de Minuit, 1987.

CAVEING, Maurice. Le problème des objets dans la pensée mathématique. Paris: Librairie Philosophique J. Vrin, 2004.

CHAUVIRE, Christiane. Mathématique et Anthropologie chez Wittgenstein. França: 2004. 29 páginas. Disponível em: <http://www.univ-paris7.fr/philomathique/Chauvire03-06-04.pdf.> Acesso em: 20 julho de 2004.

CHEVALLARD, Yves. La transposicíon didáctica. Buenos Aires: Aique Grupo Editor, 2005.

DUVAL, Raymond. Sémiosis et pensée humaine: Registres sémiotiques et apprentissages intellectuels. Berna: Peter Lang, 1995.

DUVAL, Raymond. Registros de representações semióticas e funcionamento cognitivo da compreensão em matemática. In: MACHADO, Silvia Dias Alcântara (Org.) Aprendizagem em Matemática: registros de representações semióticas. São Paulo: Papirus, 2003, p. 11- 33.

FOUCAULT, Michel. A arqueologia do saber. Rio de Janeiro: Forense Universitária, 1995.

FREGE, Gottlob. Sobre a justificação científica de uma conceitografia. São Paulo: Abril Cultural (Os pensadores), 1983.

GRANGER, Gilles-Gaston. Filosofia do estilo. São Paulo: Perspectiva, Ed. da Universidade de São Paulo, 1974. 
GRANGER, Gilles-Gaston. Pensamento formal e Ciências do homem I. Lisboa: Editorial Presença, 1975.

LIZCANO, Emmánuel. Imaginario colectivo y creación matemática: La construcción social del número, el espacio y lo imposible en China y en Grecia. Barcelona: Gedisa Editorial, 1993.

PANZA, Marco. Platonisme et intentionnalité. In: PANZA, M., SALANSKIS. J., L'objectivité mathématique: Platonismes et structures formelles. Paris: Masson, 1995. (p. 85109).

PIAGET, Jean. O Estruturalismo. São Paulo: Difusão Européia do Livro, 1974.

SILVA, Circe Mary Silva. Marco do Ensino Superior da Matemática no Brasil. TEMAS \& DEBATES, Blumenau, n. 4, p. 31-39, 1994.

SILVEIRA, Marisa Rosâni Abreu da. A interpretação da matemática na escola, no dizer dos alunos: ressonâncias do sentido de "dificuldade". Porto Alegre: UFRGS, 2000. Dissertação (Mestrado).

SILVEIRA. Marisa R. Abreu da. Produção de sentidos e construção de conceitos na relação ensino/aprendizagem da matemática. Porto Alegre: UFRGS, 2005 (Tese de doutorado).

UPINSKY, Arnad-Aaron. A perversão matemática. Rio de Janeiro: F. Alves, 1989.

WITTGENSTEIN, Ludwig. Da certeza. Lisboa: Edições 70, 2000.

WITTGENSTEIN, Ludwig. Gramática Filosófica. São Paulo: Edições Loyola, 2003.

WITTGENSTEIN, Ludwig. Investigações Filosóficas. Rio de Janeiro: Coleção Pensamento Humano, 1996.

WITTGENSTEIN, Ludwig. Observaciones sobre los fundamentos de la matemática. Madrid: Alianza Editorial, 1987. 